PAPER • OPEN ACCESS

On the periphery of university physics: trainee physics teachers' experiences of learning undergraduate physics

To cite this article: Johanna Larsson and John Airey 2021 Eur. J. Phys. 42055702

View the article online for updates and enhancements.

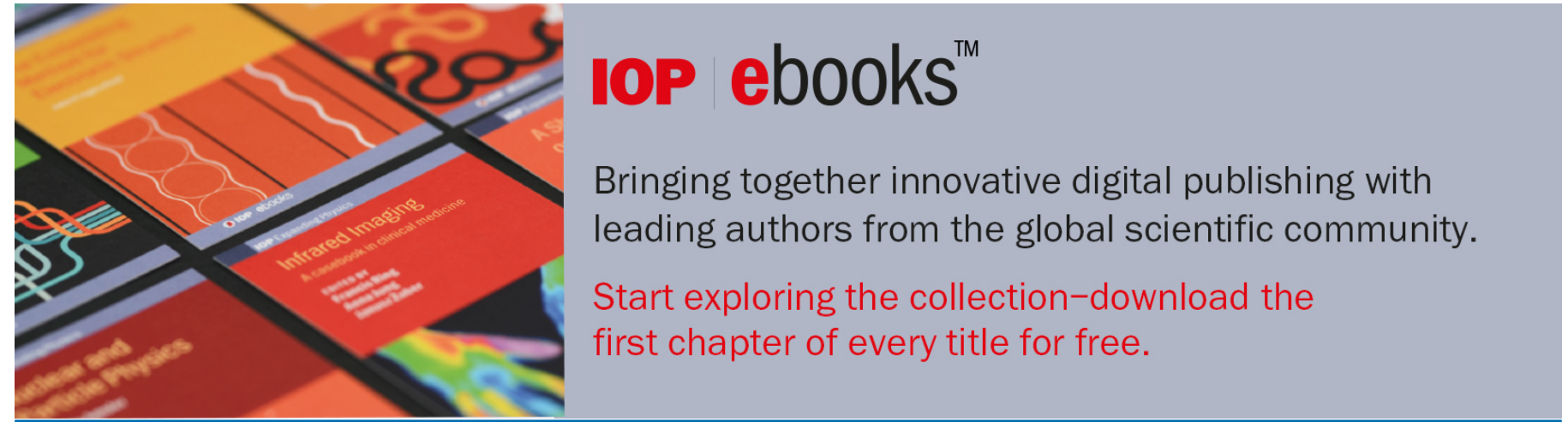

This content was downloaded from IP address 130.238 .189 .99 on $23 / 08 / 2021$ at $14: 43$ 


\title{
On the periphery of university physics: trainee physics teachers' experiences of learning undergraduate physics
}

\author{
Johanna Larsson ${ }^{1, *}$ (1) and John Airey ${ }^{1,2}$ (]) \\ ${ }^{1}$ Physics Education Research, Department of Physics and Astronomy, Uppsala \\ University, Box 513, SE-751 20 Uppsala, Sweden \\ 2 Department of Mathematics and Science Education, Stockholm University, SE-106 \\ 91 Stockholm, Sweden \\ E-mail: jola6364@gmail.com
}

Received 12 January 2021, revised 31 May 2021

Accepted for publication 23 June 2021

Published 16 July 2021

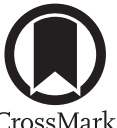

\section{Abstract}

High school physics teachers have a difficult job to do. On the one hand, they are charged with contributing to the creation of a scientifically literate society, while on the other they play a pivotal role in the recruitment of future physicists. Given the importance of this dual role, one might expect that the training of future physics teachers would be a priority for any physics department. However, research suggests that this is often not the case. While concerns have been raised about future physics teachers' understanding of physics content, less work has focussed on the sociocultural experiences of the learning environments trainees meet when learning undergraduate physics. This case study examines how a sample of trainee physics teachers perceive learning undergraduate physics content together with engineering and physics bachelor students in a large, high-status, research-oriented physics department. The findings aim to be of interest to physics lecturers when examining their own practice. We interviewed 17 trainee physics teachers about their experiences of learning undergraduate physics, how they perceived the relevance of their physics courses for their future role as teachers, and how this affected their physics learning. Here, we identified four central themes of the students' experiences: (1) teacher programme invisibility, (2) passive classroom culture, (3) perceived relevance of physics courses, and (4) no incentive to do well in physics. We discuss how this study illustrates the potential struggles trainee physics teachers may encounter

*Author to whom any correspondence should be addressed.

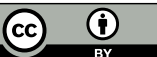

Original content from this work may be used under the terms of the Creative Commons Attribution 4.0 licence. Any further distribution of this work must maintain attribution to the author(s) and the title of the work, journal citation and DOI. 
when learning undergraduate physics. We also suggest how our findings may be used to inform the practice of university physics lecturers who come in contact with trainee physics teachers, and comment on the structure and organization of physics teacher education as a whole.

Keywords: undergraduate physics learning, student experiences, relevance, motivation, physics teacher education

(Some figures may appear in colour only in the online journal)

\section{Introduction}

High-school physics teachers have an important mission to fulfil in guiding students in their acquisition of physics knowledge as well as passing on an understanding of the significance of the subject of physics to a new generation of students. Amid calls to increase recruitment in science and technology (European Commission 2004), growing concern about the low quality of science teaching (Evagorou et al 2015), and unequal recruitment and participation in physics (European Commission 2015, Forsman 2015, Hodapp and Hazari 2015), the physics teacher's ability to provide accessible, pedagogical and equitable physics teaching is of growing importance (Osborne and Dillon 2008). This ability may well come naturally to some trainee physics teachers, but for the majority, it is something we would like them to learn while studying physics at university. Concerns have been raised about the quality and amount of physics knowledge provided to future physics teachers (T-TEP 2012). In many cases, trainee physics teachers learn physics by participating in university physics courses given by physicists (Massolt and Borowski 2020, Vollmer 2003). In addition to providing content knowledge, studying physics is also a primary source of practical experience of how physics teaching can be organised. This is significant because teachers' own experiences of learning have been shown to have an important influence on how they conceptualize good teaching (Cox 2014, Oleson and Hora 2014). While the Physics Education Research community has generated a large amount of knowledge on the practice of teaching and learning physics that could benefit school physics teachers, trainees' university physics learning rarely provides this kind of experience (Fraser et al 2014).

Trainee understanding of specific physics concepts has been thoroughly explored in the literature (Aiello-Nicosia and Sperandeo-Mineo 2000, Ding and Zhang 2016, Kaltakci-Gurel et al 2016, Mäntylä 2011, Viennot 2019). However, we know much less about the experiences of trainee physics teachers while learning undergraduate physics. In this case study, we focus on trainee physics teachers who are learning undergraduate physics as part of their physics teacher programme at a large research dominated university in Sweden. The study provides an illustrative example of the experiences of these trainees when studying together with other programme groups. The findings aim to be of interest to physics lecturers when examining their own practice. The results are based on thematic analysis of 17 semi-structured interviews with trainee physics teachers who were asked to reflect on their experiences of learning physics. To this end our research question is: How do trainee upper secondary physics teachers experience the purpose and goals of their undergraduate physics learning, when studying physics together with other programme students? Drawing on what we know from the PER literature, we discuss the effects these experiences might have on the trainees' physics learning. 


\section{Previous research}

\subsection{Physics content courses and teacher education}

International studies identify large variations in how physics teacher education is organized both across and within countries (Evagorou et al 2015, T-TEP 2012, Vollmer 2003). However, two basic models can be distinguished. In the first, physics content, didactics, pedagogy, and school practice is interwoven into a single teacher degree, given by either a specialized institution or a university. In the other, an initial physics degree (or equivalent) is followed by a postgraduate year containing pedagogy, didactics, and school practice. In some cases, this year is studied at a university, in others the training takes place more or less entirely in school (as in the 'teach first' initiatives common in England and increasingly in Sweden (Teach for Sweden 2020)). In Europe, trainee teachers are to a large extent taught physics within physics departments by physicists and physics education professionals (Evagorou et al 2015, Mäntylä 2011, Vollmer 2003). In Sweden, as well as in Germany, trainee physics teachers on the interwoven programme generally study physics courses that have been designed for the bachelor of physics programme together with other physics students (Massolt and Borowski 2020). This arrangement can also be found in Finnish mathematics teacher education (where 20\% of the trainees also take physics) (Koponen et al 2016). This model of physics teacher education, where trainee teachers learn physics from physicists together with potential future researchers and engineers, has been identified as problematic in several ways (Fraser et al 2014, Mäntylä 2011, McDermott et al 2000, Nachtigall 1990). One concern is that trainees are not taught how to transform undergraduate physics content to a level that is relevant for use in schools (Fraser et al 2014). Another concern is that physics faculty may not necessarily use teaching methods that have been shown to be effective-typically, the traditional lecture-based teaching style of university professors does not provide a good model for teaching physics in schools (Mäntylä 2011, Nachtigall 1990). Here, one proposed solution is that trainee teachers should be taught physics in the way they will later be expected to teach themselves, fostering 'productive habits' that teachers later can fall back on (Etkina et al 2017). Previous research has further investigated trainee physics teachers' learning of specific physics content (Aiello-Nicosia and Sperandeo-Mineo 2000, Mäntylä 2011, Mäntylä and Koponen 2007, Selçuk 2010, Ünlü 2010, Viennot 2019) difficulties and misconceptions in physics (Kaltakci-Gurel et al 2016, Şahin and Yağbasan 2012), as well as their epistemological development (Ding and Zhang 2016, Fazio et al 2012).

Much research has focussed on documenting characteristics of thriving physics teacher education programmes in the US. Several extensive reviews of the literature on physics teacher preparation as well as empirical investigations of thriving programs have identified physics department commitment to physics teacher education as the most important factor for success (Scherr et al 2017, Scherr and Chasteen 2020). Physics departments actively working to recruit trainee teachers, together with strong collaboration between education and physics departments, high quality mentoring, and strong disciplinary preparation have further been identified as distinguishing characteristics of thriving programs (Scherr and Chasteen 2020). Note, however, that these findings are mainly based on documenting good practice-very little empirical research is available that explores how trainees experience their educational programme (Scherr and Chasteen 2020).

It has further been suggested that departments should 'present teaching as a valid career choice $[\ldots]$ develop a welcoming and encouraging environment that shows respect for the scholarship and practice of teaching [...] encourage their best students to consider teaching and $[\ldots]$ promote teaching as an intellectually challenging endeavour' (T-TEP 2012, p 
23). The ways in which physics departments approach physics teacher education, and especially the support and discussion of teaching as a valid career option, are important factors in increasing the recruitment of trainee teachers (Marder et al 2017). This is of concern since physics faculty have been shown to inadvertently undervalue the role and status of school physics teachers, framing teaching at pre-university level as a lesser choice than a career in a physics department or in industry (Scherr et al 2015). In our earlier work we investigated how teacher educators describe the system of physics teacher education. Here we found that physicist talk about teacher education was framed within what we termed the 'physics expert model' (Larsson et al 2018, 2021). In this framing, it was assumed that the physics courses given to trainee teachers were primarily a means to create physics experts - teachers were thus not the implied students (Ulriksen 2009) in these courses. Similarly, this assumption has been shown to extend into school physics, where it may be viewed as a 'pipeline' to university physics (Osborne and Dillon 2008, p 7). This raises concerns about how trainee physics teachers come to understand the role of their university physics courses in relation to the school physics they are preparing to teach. In this paper we therefore investigate how trainee physics teachers experience the purpose and goals of their undergraduate physics courses in relation to their future.

To describe teachers' knowledge base Shulman (1986, 1987), developed the notion of pedagogical content knowledge (PCK). Trainee physics teachers learn content knowledge from physicists and pedagogical knowledge at the education department. These two sources of knowledge intersect in PCK which is defined by Shulman (1987) (p 8) as 'that special amalgam of content and pedagogy that is uniquely the province of teachers, their own special form of professional understanding'. PCK has been widely used and has subsequently evolved into a family of related concepts, pointing towards the complex interplay between disciplinary content knowledge and what is needed for teachers to effectively teach this knowledge (Berry et al 2015). For example, Park and Oliver (2008) conducted an extensive literature review, thereafter defining PCK as 'teachers' understanding and enactment of how to help a group of students understand specific subject matter using multiple instructional strategies, representations, and assessments while working within the contextual, cultural, and social limitations in the learning environment' ( $\mathrm{p}$ 264). They argue that PCK simultaneously represents teachers' understanding and their enactment of this understanding. This means that PCK cannot only be passively received but needs to be created by teachers through their own experiences.

In physics, PCK includes knowledge of students' ideas, including 'misconceptions' and prior knowledge, how to deal with such conceptions, the appropriate use of metaphors, representations and ways to measure the learning of students (Milner-Bolotin et al 2016, Thompson et al 2011). In physics teacher education, a closely related concept, content knowledge for teaching (CKT) is often invoked (see for example Etkina et al 2018, Loewenberg Ball et al 2008). In the context of teaching mathematics, Loewenberg Ball et al (2008) suggest that teachers need specialized content knowledge that is not related to student understanding or teaching, but that is still unique to teachers. This specialized content knowledge involves 'an uncanny kind of unpacking of mathematics that is not needed - or even desirable-in settings other than teaching'. In physics, Seeley et al (2019) (p 510) have shown that teachers 'who demonstrate a strong understanding of a systems approach to energy analysis are also better equipped to respond productively to student reasoning about a system approach to energy'. This is one example of the specialized physics content needs of trainee physics teachers. With a majority of teaching now moving online, the significance of trainees also learning technological pedagogical content knowledge (TPCK) (Mishra and Koehler 2006) is increasing. The extensive literature on PCK and CKT shows the complexity and importance of trainee physics teachers' learning for how physics content is taught. Several successful programmes that facilitate the 
physics learning of trainee teachers have been created such as physics by inquiry (McDermott et al 2000), the Colorado Learning Assistant Programme (Otero et al 2010) and the Physics Teacher Preparation Programme at Rutgers (Etkina 2010). The need for specialized physics courses for trainee physics teachers has long been a topic of discussion (McDermott 1990) and these examples highlight the ongoing work on the specific physics needs of trainee teachers. However, reflection on the specific role of physics content courses in physics teacher education still seems to be rare outside these contexts. For example de Winter and Airey (2019), asked 324 stakeholders across England about the "key attributes of a "good" secondary school (11-18) physics teacher'. While physics content knowledge was high on this list of attributes, very few of the stakeholders actually specified the level or nature of the physics knowledge required. Similarly, Frågåt, Hendriksen and Tellefsen (2021) found that while in-service physics teachers emphasized the importance of physics content knowledge, they did not tend to connect content knowledge with pedagogical knowledge to express the integrated nature of PCK.

Finally, trainee teachers' experiences of learning physics are central to their future task to create a physics classroom environment that 'values and includes non-dominant students' (Gosling and Gonsalves 2020, p 343). For example, the high school physics experience, and especially recognition from physics teachers, has been shown to be a critical factor for whether women decide to continue with physics (Hazari et al 2017). Another factor is explicit classroom discussion of women's underrepresentation in physics (Hazari et al 2013). Stereotypes that depict physicists as particularly gifted have also been identified as negatively affecting non-dominant students' ability to identify with physics (Gosling 2020). In a study of upper secondary school physics students' classroom interactions, a storyline of 'mastering physics' associated with 'smartness' was found to be connected to whether students become 'insiders' to physics (Berge et al 2020). Storylines such as these contribute to a classroom environment where asking questions or expressing uncertainty or confusion about physics content are inhibited-all practices that have been shown to be positively correlated with physics students' examination results (Dowd et al 2015).

\subsection{Relevance and motivation}

The experiences of non-physics majors when learning physics have been thoroughly examined in the literature. One key finding in this work is the significance of perceived relevance. Students who experience relevance in their physics courses have been found to have better learning outcomes and motivation (Afjar et al 2020, Bennett et al 2016, Descamps et al 2020, Gaffney 2013, Geller et al 2018, Nair and Sawtelle 2019, Plomer et al 2010). For example Plomer et al (2010), showed that adapting physics laboratory work specifically to the needs of medical students resulted in higher test scores, both in the adapted content and on 'pure physics questions'. Furthermore, the students' motivation and their enjoyment of the course increased. For non-science majors, finding physics content relevant to their future career has been shown to be a strong predictor of motivation to learn (Bennett et al 2016). Similarly, programme affiliation and perceived relevance of course content has also been connected to performance differences of students taking the same physics course (Andersson and Johansson 2016). A quantitative study of 329 Finnish physics students' aspirations and motivations found that self-efficacy and positive intrinsic motivation (that is, studying physics for its own sake rather than as a means to an end) predicted the students' aspirations for continuing with physics (Barthelemy and Knaub 2020). Worryingly, these factors were also found to have lower values for the female respondents. All this work highlights the importance of perceived relevance of physics studies for student performance.

In his thesis work van Dusen (2015), suggests that student motivation is connected to their sense of belonging in the classroom and willingness to engage in active exploration of physics. 
Rather than being a property of the individual student, motivation is here viewed as a feature of the learning environment. Van Dusen suggests that student 'motivation can be altered by setting up a context in which competence and autonomy are more likely to be expressed as improvement of the self/environment and self-expression/innovation rather than as selfesteem maintenance and alienation'. Similarly, in their qualitative case study of life-science majors' experiences of learning physics Nair and Sawtelle (2019), challenge what they call the 'deficit interpretations' of students' ability to see physics as relevant. They argue that the use of large-scale surveys such as CLASS or MPEX to measure student beliefs about relevance, risks framing such beliefs as a cognitive property of the students themselves. In such studies, experiencing lack of relevance is thus interpreted as a failure on the part of the students rather than a failure of their physics courses to demonstrate such relevance. Nair and Sawtelle's study highlights the importance of the interplay between the physics classroom and students' disciplinary experiences as a way to create connections that are relevant to students. Inspired by this approach, we have adopted one of that study's research questions to guide our analysis, namely: 'Will students find meaning or value in physics beyond its purpose in the classroom?' (Nair and Sawtelle 2019, p 4)

Some research has been carried out into trainee teachers experience of relevance of their physics courses (Gaffney 2013, Körhasan 2015). Gaffney (2013) investigated student expectations and affect in an astronomy for teachers course given by the University of Kentucky and found that not meeting student expectations resulted in negative assessment of the course. 'This study suggests that such negative affect arises within the classroom when students are unsure of the role of the course within their professional development' (p 13). The authors point out the need for science teachers to have positive experiences of learning science, and thus the importance of avoiding negative affect with respect to physics. Körhasan (2015) investigated trainee teachers motivation in learning quantum theory, using expectancy-value theory. Elements found to affect motivation to learn quantum theory were the instructor, previous performance in the quantum physics course, and the nature of quantum mechanics content.

In summary, the physics learning of trainee teachers has been examined from the perspective of understanding specific physics content, trainees' particular needs in terms of exposure to teaching practices, and the importance of relevance for non-physics majors. The model of physics teacher education that builds on non-specialized, shared physics courses has also been identified as problematic in the literature. However, little research has focussed on the particular dynamic of trainees learning physics together with other programme groups. In this respect, we strive to contribute to this strand of research through a qualitative exploration of how trainee teachers describe their experiences of studying physics on such courses.

\section{The study}

\subsection{Research context}

The case is focussed on a university-based, upper secondary physics teacher programme given at a large Swedish research university. In Swedish accreditation standards, upper secondary school teachers qualify to teach two subjects. Here physics must be paired with mathematics (note: mathematics can be paired with other subjects). The programme consists of ten semesters (of 20 weeks each), and is of the interwoven style, alternating between educational science, school placement and subject matter studies. In total, trainee physics teachers take 40 weeks of educational science. This includes Swedish history of education, leadership, theory 


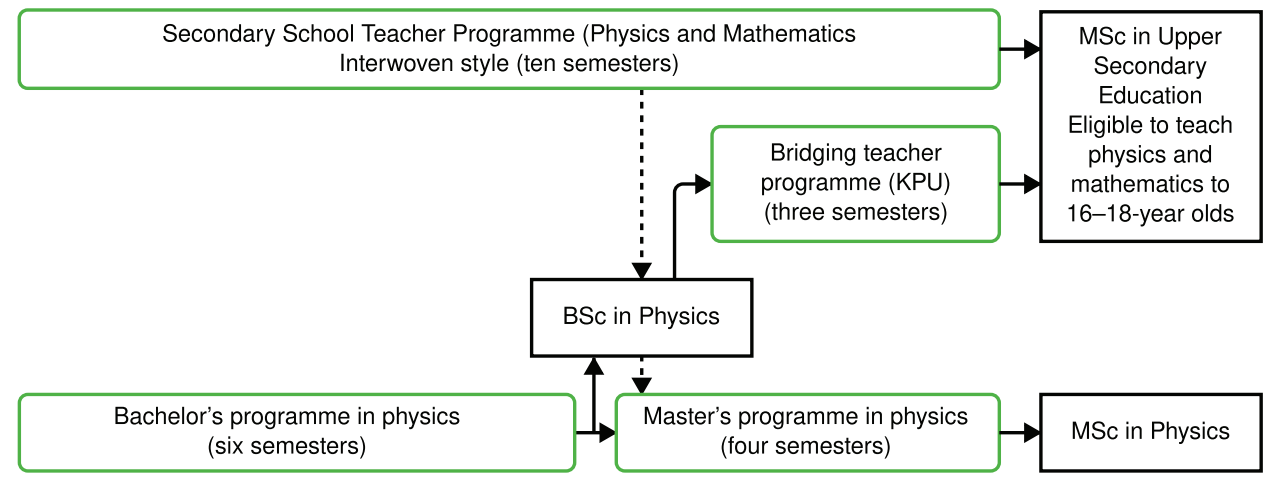

Figure 1. Degree pathway flowchart. Students on the Secondary School Teacher programme can receive a Bachelor degree in physics by choosing an appropriate degree project. They may then continue on the Master's programme in physics (dotted arrows). Conversely, students on the bachelor programme may choose to become physics teachers by adding a postgraduate teaching degree of three semesters (the bridging teacher programme).

of learning and development, special education, curriculum theory, and assessment and grading. The programme also includes 20 weeks of school placement, 80 weeks of physics and 60 weeks of mathematics. The majority of the subject matter courses are studied together with the physics bachelor programme (physics majors, usually with an elective in mathematics), and include calculus-based mechanics, thermodynamics, electromagnetism, waves and optics, quantum mechanics, astrophysics, energy physics, and modern physics. Neither physics nor mathematics courses are specifically tailored to trainee teachers' needs. Trainee teachers also take a six-week course of what in Swedish is called 'physics didactics' (fysikdidaktik) as part of their physics coursework. These courses focus on teaching physics, utilizing the knowledge base of Physics Education Research.

The physics Bachelor programme at the university in question is considered a high-status programme, with a strong focus on research-oriented physics content. The physics lecturers who teach at the department are in most cases also involved in physics research, and do not have a background in physics education research or teaching. A requirement for teaching at the department is participation in a full-time, five-week academic teacher training course. This course includes general theory and practice about teaching and learning in higher education, and is not specific to teaching higher education physics. Large scale lecturing followed by problem solving sessions dominate the physics teaching, even though some professors are actively involved in using evidence-based teaching methods. After finishing their degree, bachelor students may choose to become physics teachers by adding a postgraduate teaching degree of three semesters (the bridging teacher programme). This entails two semesters of educational courses and one semester of school placement. Conversely, trainee physics teachers can receive a bachelor degree in physics or mathematics in addition to their teaching degree by choosing an appropriate degree project. A visual representation of these degree paths can be found in figure 1 . The students studying physics together thus consist of trainee physics teachers explicitly enroled on a teacher programme (but who might choose to also earn a bachelor in physics), bachelor students who are planning to take the postgraduate teaching degree, bachelor students who are considering the postgraduate teaching degree, and bachelor 
students aiming towards research or other physics-related futures ${ }^{3}$. The gender distribution in the physics teacher programme and the Bachelor programme - as indicated by legal gender reported in the system - has hovered around 20\% women over the last ten years. In Sweden, specific information about students' ethnicity or economic background is not available on programme level. However, the student body is pre-dominantly white and middle-class. In the selection of interviewees for this study, women amounted to $30 \%$, where gender was indicated by self-identification. According to Swedish ethical regulations, ethnicity is considered sensitive personal information and storing such information requires a specific permit. This information was thus not collected about the interviewees.

A note about our labelling of the different student groups. Throughout the interviews, the interviewees refer to themselves as 'trainee teachers' and the other programme students as 'bachelor students' and 'engineering students'. However, since some teacher trainees receive bachelor degrees in physics, and some students registered on the bachelor programme are on their way to becoming teachers, this terminology is sub-optimal. To differentiate the student groups, we refer to the students on the physics bachelor programme who are not becoming teachers as physics programme students. We use the term undergraduate physics students when referring to the whole group of students who are learning physics together.

\subsection{Data collection}

Empirical data was collected through interviews with trainee physics teachers on years two and three of the interwoven programme. Students on the bachelor programme who planned to take the postgraduate teaching certificate were also asked to participate. To provide background information used to facilitate interpretation of interview data, the courses the students were currently taking were observed during the interview period. For the year three students this entailed observation of courses in physics and mathematics, whereas for year two students the interviews took place during their first contact with education courses after studying physics in their first year. These observations were also used as the primary source of recruitment for the study, identifying students who were trainee physics teachers or who were planning to take the postgraduate year and asking whether they would agree to participate in an interview. In year two of the interwoven programme, six students out of nine agreed and in year three, five out of seven agreed. Four additional students were interviewed who were studying at an individual pace due to health or personal reasons. Finally, two of the interviewed students identified themselves as bachelor students who were planning to take the postgraduate teaching certificate. See table 1 for an overview of all interviewees. For the analysis, we chose to treat all of these students as one pool of data, and did not differentiate between programme paths. The primary reason for this choice was that all of the students studied physics together in the same classes, and all see themselves on a path to become physics teachers.

The 17 semi-structured interviews (Kvale 1996) were carried out in Swedish and lasted between 45 and 90 minutes each. In compliance with Swedish Ethical Research Standards (Swedish Research Council 2017) the students were informed of the purpose of the study and their right to withdraw at any time. They were informed about confidentiality and asked to sign a document confirming that they had received the information and that they consented to be

\footnotetext{
${ }^{3}$ The precise number of students studying each variation of the system is unclear. This is because when students move between the different programmes or leave the programme, this is not immediately documented in the system. When starting their studies, the two cohorts in focus in this paper each consisted of approximately 10 teacher trainees, 40 physics bachelor students and 130 engineering students.
} 
Table 1. Overview of interviewees.

\begin{tabular}{lcc}
\hline Pseudonym & Study year & Interview duration \\
\hline Elin & 3 & $01: 16: 19$ \\
David & Individual study pace & $01: 22: 01$ \\
Marcus & Individual study pace & $00: 53: 15$ \\
Tom & 2 & $01: 30: 42$ \\
Hampus & 3 & $01: 26: 28$ \\
Finn & 2 & $01: 13: 06$ \\
Julia & 3 & $01: 16: 37$ \\
Niklas & Individual study pace & $01: 35: 03$ \\
Amanda & Bachelor student & $02: 00: 00$ \\
Magnus & 2 & $01: 40: 50$ \\
Alex & 2 & $01: 33: 50$ \\
Isak & 3 & $01: 26: 31$ \\
Daniel & 2 & $01: 14: 51$ \\
Katja & 2 & $00: 44: 38$ \\
Andrej & Individual study pace & $01: 44: 14$ \\
Ellen & 3 & $02: 14: 32$ \\
Dennis & Bachelor student & $01: 30: 17$ \\
\hline
\end{tabular}

recorded during the interview. One student chose to not be recorded and, in this case, extensive notes were instead taken during the interview.

The interview guide was developed to touch on a number of aspects of trainee experiences of learning physics, as well as to provide a dynamic interview flow, allowing the interviewer to be flexible and investigate significant experiences that the interviewee gravitated towards. Care was taken to choose questions that encouraged interviewees to describe situations, thoughts and feelings, rather than speculating on why something happened (Flick et al 2007). To ensure that the guide captured the central themes around the research question, a first draft was piloted with a physics graduate who had just entered the bridging teacher programme. This trial run resulted in some questions being discarded and the overall language of the guide simplified, lowering the complexity of the interview, and narrowing the focus.

Following the introduction and background questions, interviews were guided by five open themes: the decision to become a physics teacher, what a physics teacher should know, trainee physics teachers compared to other students, the physics subject itself, and experiences of the physics teacher programme. Under the theme 'what a physics teacher should know' some of the included questions were: what is important knowledge for a trainee physics teacher to learn and what part of the education should contain this? Are there parts of your education that you experience as more relevant to your future? Are there parts you find less relevant? Do you think something is missing in your education? The answers to these questions together with the more open 'tell me about your experience studying physics' constitute the main data used in the analysis. However, in the first open thematic coding, the whole material was included and any student answers relevant to the study were identified for further analysis.

The entire collected material consisted of $24 \mathrm{~h}$ and $43 \mathrm{~min}$ of interviews supported by $26 \mathrm{~h}$ of classroom observation. All interviews were transcribed verbatim. The quotes used in this article have been translated from Swedish by a native English speaker who is also fluent in Swedish, paying particular attention to the meaning of the quotes rather than a word-for-word translation. Round brackets in quotes denote the interviewee doing something, such as laughing. Curly brackets mark utterances made by the person not currently talking, usually affirmative sounds. 
Square brackets are used for editor comments. Three dots in square brackets mark part of the transcript has been removed for clarity of reading purposes, taking care that the removed part does not alter the meaning. Italics are used to direct the reader's attention to a particular piece of text.

\subsection{Analysis}

This article is part of a larger project that views learning to become a physics teacher in terms of becoming fluent in a set of new discourses (Gee 2005). Thus, in this characterisation, physics teacher education involves learning to function within socially agreed systems of talking and acting. Thematic analysis was used where the generated themes are understood as patterns in the discourse of the trainee physics teachers (Braun and Clarke 2006). In the first open coding the whole material was read through and coded with a focus on student described experiences of learning physics. This resulted in 102 separate codings. Each individual coding was then read through and its relevance for the research question 'how do trainee physics teachers experience the purpose and goals of their learning undergraduate physics?' was considered. Codings were merged and those that were deemed less relevant for the focus of this paper were set aside. This resulted in four major themes: teacher programme invisibility, passive classroom culture, perceived relevance of physics courses and no incentive to do well in physics. The invisibility theme consisted of student answers that dealt with experiences of being noticed or not noticed, as a group. The passivity theme consisted of comments on classroom norms. The relevance theme consisted of students reasoning around the question 'how do students find meaning or value in physics beyond its purpose in the classroom?' (Nair and Sawtelle 2019). The incentive theme consisted of discussions of grades or efforts made to learn physics. The quotes for each theme were read through and sorted into sub-themes, seeking to explore the different experiences described in the material.

It was not possible to ask interviewees to member-check the transcripts. However, when a first draft of the analysis was written up, the four analytical themes were presented to, and discussed with, three of the interviewees. While this falls short of systematic member checking (Guba and Lincoln 1982) of the results, the three students did recognize and identify with the themes. We take this as an indication that our results resonate with at least part of the interviewee group.

Frequency counts are reported for the main themes of the analysis, see table 2 . Note that the number of coding instances in each theme should not be seen as quantitative support for the trustworthiness of our results. While we do report on student experiences that exist and are significant in our case study, we are not claiming that these experiences are directly generalizable to other student groups. Rather, in accordance with an understanding of the validity of qualitative research as a process of crystallization (Taylor 2014), we seek to describe one facet of trainee experiences. This facet is naturally dependent on the particular angle provided by the context of our case, our particular way of interviewing etc. However, we suggest that our results will have resonance (Tracy 2010) with physicists and physics teacher educators who can use them to reflect on their own experiences of trainee physics teachers in their particular context (Guilfoyle et al 2020).

\section{Findings}

The main findings of this study are four central themes describing trainee physics teachers' experiences of studying physics together with other programme groups as part of physics teacher education. These themes are: teacher programme invisibility, passive classroom culture, perceived relevance of physics courses, and no incentive to do well in physics. For an 
Table 2. The four main themes with sub-themes describing student experiences reported on in this paper. Note that coding frequency is reported to provide transparency and should not be interpreted as evidence of generalizability or consistency among student experiences.

\begin{tabular}{ccc}
\hline & $\begin{array}{c}\text { Number of Number of } \\
\text { Themes }\end{array}$ & Number of Number of \\
mentioning instances & Sub-themes & $\begin{array}{c}\text { interviewees coding } \\
\text { mentioning instances }\end{array}$ \\
\hline
\end{tabular}

\begin{tabular}{|c|c|c|c|c|c|}
\hline $\begin{array}{l}\text { Teacher programme } \\
\text { invisibility }\end{array}$ & 8 & 29 & & & \\
\hline $\begin{array}{l}\text { Passive classroom } \\
\text { culture }\end{array}$ & 13 & 11 & & & \\
\hline \multirow[t]{7}{*}{$\begin{array}{l}\text { Perceived relevance of } \\
\text { physics courses }\end{array}$} & 17 & 155 & $\begin{array}{l}\text { Need to know school } \\
\text { level physics }\end{array}$ & 14 & 32 \\
\hline & & & Providing inspiration & 15 & 22 \\
\hline & & & Questioning relevance & 13 & 47 \\
\hline & & & Personal gain & 9 & 34 \\
\hline & & & Provides high status & 6 & 7 \\
\hline & & & Instrumental motivation & 5 & 10 \\
\hline & & & A real physics experience & 2 & 3 \\
\hline $\begin{array}{l}\text { No incentive to do } \\
\text { well in physics }\end{array}$ & 9 & 11 & & & \\
\hline
\end{tabular}

overview of the themes and sub-themes together with their prevalence in the interview material, see table 2 . The themes build on analysis of a number of coding instances and no quote alone is the sole source of the interpretations of the theme. The quotes presented here are thus illustrations and should not be taken to be the sole source of any theme.

\subsection{Teacher programme invisibility}

Learning physics together with physics programme students and engineering students, the trainee teachers experience their visibility as limited on a programme level. The trainee teachers describe feeling they are not treated in the same way as the other programme groups. Andrej says:

Andrej: If you study with the physics programme students, then the focus is not so much on the trainee teachers, but rather it is a physics programme course. It is the same when we have courses together with the engineering students, then it is an engineering course [...]. There have been courses where they do not, where [the physics lecturers] have not checked that there are trainee teachers in their-like in the course.

To Andrej, the agenda when studying physics together seems to be defined by the other participating programmes, and physics lecturers do not acknowledge that trainee teachers are present. This experience of invisibility is further reinforced when physics projects are tailored to accommodate the needs of other programme groups, but no such accommodation is made for trainee teachers:

Andrej: All of those groups had a specific project tailored to their programme, but we just had nothing (laughing). So, we were asked to just, yeah well, choose one of those other projects.

Elin describes a similar experience: 
Interviewer: And if you're studying at [the physics department], is it noticeable somehow, that you are a trainee teacher?

Elin: [...] What is noticeable is that they often forget about us (laughing). Like in [course name] for example, they had forgotten, uh, that we were taking that course, so there were no lectures scheduled for us $\{\mathrm{mm}\}$ and no project planned, we kind of had to organize that ourselves.

Analysis of the interview transcripts shows that the physics teacher programme is experienced as mainly being designed around what already exists for other programmes. The trainees feel that little thought has been given to how or why such courses might be suitable for teachers-making the programme progression appear haphazard rather than purposefully thought through. Daniel summarizes this view when he says that he is looking forward to taking pedagogy courses next semester because it will make it feel like 'you are part of a teacher programme, not just a physics programme'. In this way, the trainee physics teachers experience invisibility on a programme level, feeling that they are learning physics based on the needs of other student groups.

\subsection{Passive classroom culture}

The theme passive classroom culture captures how trainee physics teachers experience the physics classroom ${ }^{4}$. The trainees describe how they hesitate to carve out visible spaces for themselves in class, due to the risk of giving the wrong answer and thus being perceived as not good enough. They describe a culture within the physics classes, where the majority of the students do not ask nor answer questions. One example is given by Tom:

Interviewer: Would you say that there are some norms- that you need to act in a particular way to fit in?

Tom: [...] Physics students are not good at answering questions [erm] that are put to the whole group and, that has been clear for a long time [...] it's almost an unwritten rule, that no [physics student], and not just the trainee teachers but also the physics programme students, no one answers the question [...] I guess it has something to do with not wanting to give the wrong answer and always being sure of the answer before speaking up.

Interviewer: That shyness, or that unwillingness to be wrong, can you see that anywhere else?

Tom: [...] It's not really about being shy, but for some reason you don't want to be the one who answers, it's a bit like not wanting to be the one who answered wrong.

Interviewer: How is it with asking questions, then?

Tom: We're not good at that either. It feels like most physics students want to lower their heads, take notes, and then go through those notes later to teach themselves.

Here, Tom attributes the unwillingness to ask and answer questions that he has experienced during his physics courses, to a fear of giving the wrong answer. We interpret Tom's final comment as pertaining to the general study culture among the trainee teachers, and thus indicating a

\footnotetext{
${ }^{4}$ In the quotes within this theme, most trainees do not make clear distinctions between trainees and other physics students. The experiences described here are thus likely to also hold true for the physics programme and engineering students. Note however that this assumption cannot be taken for granted, since it has been shown that programme affiliation can greatly affect how different students experience the same physics classroom (Andersson and Johansson 2016).
} 
norm of passivity, where students prefer to place their active learning outside of the classroom. Another student commenting on this same theme is Magnus:

Magnus: I would say that, at least I feel that you do not always dare to ask for help, because you do not want it to show that you do not know. I think there's an underlying thought for most people in this programme, that you are a little afraid to ask for help

Choosing to remain invisible by not asking is a way of avoiding the risk of being exposed as not knowing physics. This classroom culture seems to negatively affect the students' willingness to engage actively in physics learning. Ellen brings up this theme when she is asked about differences between studying at the physics department compared with the education department:

Ellen: [...] I think people are more willing to raise their hand at [the education department] for example, to kind of ask and say their opinion, when they open up a discussion. So it's more that someone, while at [the physics department] maybe the lecturer will say: 'is there a question? Is everyone following?' and the room is just totally silent. No one even nods, or says yes, then you see [the lecturer] just say 'Ok, ehm, I will just continue then, if there are no questions' (laughing). So, it's more that people are willing to be noticed [at the education department], like there is, it's just a more friendly environment (laughing). And so, sometimes then, of course, if it had been something that I had been really confident in, here [at the physics department] and if it had been another course, I might be more willing to say it out loud. But, it's usually more that I hesitate a bit, and when someone finally says something it's always right. It's kind of like, there's someone who will raise their hand. One person, sometimes it's no one, and it's always one of the top students, and the answer is always correct. And then you don't really want to, if you are a bit uncertain, to answer, and then if it's wrong, $\{\mathrm{mm}\}$ because it's this culture that you want to appear just as capable. It's usually like that when I study with both physics programme students and engineers, that you're kind of expected to show you're good at physics.

At the physics department, Ellen experiences a classroom culture where it is important to know you have the right answer before making yourself heard. Ellen bases this on her observations of who usually speaks, it is 'always one of the top students and the answer is always correct'. In summary, the trainee students describe a classroom culture of passivity, where asking and answering questions is limited by the fear of not being right.

\subsection{The perceived relevance of physics courses}

The trainee teachers speak about the relevance of their physics courses in three main ways, corresponding to the three largest sub-themes under relevance in table 2. These are: need to know school level physics, providing inspiration, and questioning relevance. In the first subtheme, the relevance of physics courses was judged in terms of their direct correspondence to school level physics. When asked whether he experiences the physics courses as adapted to his future Daniel says:

Daniel: Yes, it's on a higher level, but still things that you have, like, that you have seen and worked with at some point in secondary school. So, that, yeah it feels like these are things that will end up in my teaching. Perhaps not on this level [...] I mean I had in the beginning mechanics courses. Of course, we will have mechanics [in school]. And waves and optics. These are things you learn at some point, uh, even at secondary school and perhaps already at elementary school, on an even lower-level sort of. So yeah, in that way the physics courses feel relevant. $\{\mathrm{mm}\}$ Yes. 
In the second sub-theme, providing inspiration, higher-level courses not corresponding to school physics were described as vaguely relevant in that they can potentially provide inspiration for future physicists. Dennis said that he needs the higher-level courses to 'be able to inspire. To draw parallels and give glimpses of future areas of study'. Another example is Daniel from the quote above, now reflecting on higher level physics courses:

Daniel: I often think rather that this was interesting, but this, this is not something we talked about in secondary school. This is not something I will ever teach $\{\mathrm{mm}\}$. But... but I understand that you should... A higher... I mean more knowledge than what you will perhaps teach $\{\mathrm{mm}\}$ but... Yeah.

Here Daniel asserts the relevance of higher-level physics courses, but he does not sound convinced by his own reasoning, signalled by the 'but', the tone of his voice and seeking way of speaking. This kind of vague reasoning about relevance is representative of this theme, where a common response is to assume that higher level courses are relevant, but without identifying why: 'what [trainee teachers] will do is teach physics to others, so giving them a deeper and more detailed understanding of physics is really important' (David).

The third sub-theme, questioning relevance, was the largest theme, mirroring that the most common student response regarding the relevance of the physics courses was to question it. Two examples are Marcus and Isak:

Marcus: Why should I take [quantum mechanics]? Yes, sure, I should have a certain higher-I get the point of why. But sometimes it also feels like, I understand what the course is for, I understand what it is doing, but sometimes it feels like if you, sort of, take a step back and think about it, it feels like a pretty unnecessary, um, part of a course. Especially when it is so big.

Isak: I think it is really frustrating sometimes when I am supposed to be doing these very advanced calculations - perhaps not incredibly advanced — but [...] I guess that's my criticism of the teacher education in general, that it is not designed for teachers. When we take these courses, we just 'tag along' learning together with others-engineers and physics programme students and mathematics and so on $\{\mathrm{mmh}\}$. And sometimes perhaps you go way too deep into unnecessary, unnecessarily deep into some areas - if you know what I mean, or at least you do too many of calculations $\{\mathrm{mmh}\}$, if that makes sense.

For both Isak and Marcus, learning advanced physics feels irrelevant to their goal of becoming physics teachers. Isak also describes his frustration with finding the course goals designed for physics programme students or engineering students (who need this knowledge to qualify for later courses), which was also in the analysis coded within the earlier described theme of programme group invisibility. Similarly, Ellen fails to connect her physics courses to her future job as a teacher:

Interviewer: Is there anything you have experienced as difficult about studying to become a teacher?

Ellen: I guess it's the physics. I think that when I started in the physics teacher programme, I was thinking a little like this: Ok, I want to become a teacher. And sure, I need to know a certain level of physics, but I thought that, maybe that's not super difficult physics. Of course, you need to go deeper in all parts, but I maybe don't need to become like an expert in everything. That was totally wrong (laughing) [...] because in the beginning it was like, I felt like I was becoming just a physicist, because I saw no connection to anything, anything related to teaching at all. 
For Ellen, it did not feel like she was studying to become a physics teacher at all, rather she felt as if she was part of the physics bachelor programme. In the continuation of this quote, Ellen went on to explain that she finds physics content that corresponds to school level physics clearly relevant, while it is unclear why she needs the more advanced courses. However, the student answers in this theme were not always straightforward in questioning relevance. Hampus firmly expressed his belief in the relevance of the content corresponding to school physics, while at the same time he both questioned the relevance of what he calls 'heavier physics' and assumed that it is needed to create student interest:

Interviewer: How much physics knowledge do you think you need to become a good physics teacher?

Hampus: Above all you have to be $100 \%$ absolutely certain of the material you are actually teaching. Eh, and then I think, I'm convinced that it's important to have at least an overview of what we are learning now, that is, heavier physics. Because often there are students who are really interested and can ask questions and then I believe it's good to be able to answer and awaken their interest a bit extra $\{\mathrm{mm}\}$. So that, yeah, I sometimes think it's excessive learning quantum physics for example, when we are going to teach secondary school. But at the same time I understand, I think it's important to know something about stuff like that, to inspire students to stay in physics $\{\mathrm{mm}\}$.

In summary, we found that the trainee physics teachers express confidence in the relevance of introductory physics courses, but ambivalence to the relevance of their higher-level physics courses. The trainees often questioned the relevance of advanced courses or just assumed they were needed in some way. Combined, the three sub-themes of relevance convey a picture of physics courses with limited or uncertain relevance when they exceed content taught at upper secondary school level. A sub-set of the students do however describe the more advanced physics courses as clearly relevant to them on a personal level, these students really enjoy learning physics, even though they do not think the knowledge they learn will be especially useful for their future role as physics teachers.

\subsection{No incentive to do well in physics}

In the fourth major theme, no incentive to do well in physics, the trainees discuss how being successful in physics courses is irrelevant for their future as teachers. Being successful in physics was throughout the interviews connected to high grades ('getting fives') and although there was no direct question in the interview guide about this topic, the significance of good grades came up in just over half of the interviews, mostly in the context of discussing the differences between trainee teachers and the other student groups. We exemplify this kind of reasoning with a quote from Hampus:

Hampus: Yes, in general we have, us teachers-there are seven of us-in general our grades are worse than the physics programme students'. That's true.

Interviewer: Why is that?

Hampus: I think we don't care as much about getting fives [the highest grade]. Because it doesn't matter for our jobs anyway. But I think, I don't know that much about doing a $\mathrm{PhD}$, and going on with research and so on but, I guess it's an advantage to have fives if you are going in that direction. So that's why the physics programme students work their asses off (laughing) doing as well as possible. We can be a bit more relaxed, since we don't have this, these high expectations when entering the work-force, I believe we are not taking things as seriously $\{\mathrm{mm}\}$, it's fine to just pass, it doesn't matter if I only get a 3 [pass grade]. 
Here, Hampus assesses the importance of high grades in physics on the basis of getting a job and the conclusion is that grades are irrelevant if you are becoming a teacher. At the same time, Hampus does not appear to consider high grades in physics as a sign of having gained deeper knowledge that could be of use in a teaching career. Tom also illustrates this point:

Tom: And then within the teacher programme, it is not really important to achieve a five on all exams, it is enough to just pass. As long as you properly complete the programme, it is enough. While the physics programme students, they seem to feel more that the grades maybe have a little more weight.

Julia, Ellen and Finn, also bring up this difference when they compare trainee physics teachers with the physics programme students:

Julia: Perhaps we are perceived as taking our education more lightly, that it's a bit—it's perhaps not as deadly serious for us. Erm, which probably is true, because if you are doing a bachelor in physics the competition will be fierce if you are to stay in physics, while if you are becoming a teacher you know you will get a job anyway. So perhaps... that it's a little more we can play around a bit more, sort of.

Ellen: I noticed that the competition was much greater among the physics programme students, when we were studying together in the beginning. You had to be best at everything, they wanted fives.

Interviewer: Do you experience learning physics differently as compared to [the physics programme students]?

Finn: Yeah, yeah I believe so. Definitely, because for example, many physics programme students aim towards like getting as good a grade as possible, and they can pretty much sit and study forever. While us teachers, we just want to pass.

While some of the trainees say they do aim for higher grades in physics, none of them frame their success in physics as having implications for their future teaching career. Note that in these quotes, the students are talking specifically about grades, rather than about understanding or learning physics on a deep level. Also, just like in the case with Hampus above, grades are discussed in terms of getting a job, or getting ahead of the competition, rather than being related to physics knowledge needed for teaching. In the whole interview material, being successful in physics is equated with good grades and seen as an 'optional extra' for trainee physics teachers. Physics courses are thus experienced as something that simply need to be passed and there does not appear to be any real incentive for the trainee physics teachers to excel.

\section{Discussion}

This case study contributes to our knowledge of the undergraduate physics learning of trainee teachers by providing new insight into how these particular students experience the dynamic of learning physics together with other programme groups. Even though the research on physics teacher knowledge and thriving physics teacher education programmes is extensive, qualitative knowledge from the perspective of trainee physics teachers is scarce. We explored how upper secondary trainee physics teachers experience their physics courses, and identified four central aspects of the trainees' experiences: (1) Feeling invisible on a programme level in the physics courses. (2) Experiencing a classroom culture of passivity focussed on giving the right answers. (3) Physics content that exceeds the upper secondary school level is experienced by trainees as having limited or uncertain relevance. (4) There is a lack of incentive to be successful in physics. One way of interpreting these four themes is that they represent aspects of what it is 
like for this group of students to be part of a physics programme that is not designed primarily for them. These experiences mirror the assumptions of the 'physics expert model' that has been identified in the talk of physicists (Larsson et al 2018). In that model, the default goal of university physics teaching is to create future researchers in physics.

Trainee teachers' lack of motivation to excel can be understood as another aspect of the theme of invisibility, since the grading scheme in physics is designed with the needs and goals of physics programme students in mind. In order to stand out as successful, a trainee physics teacher would need to strive for good grades without the incentive of these grades having more than a peripheral bearing on their future career opportunities as a physics teacher. The four themes thus convey an image of marginalized trainee physics teachers learning physics on the periphery of university physics education, with the bachelor and engineering programmes at the centre. The trainee teachers do not experience a commitment to physics teacher education on the part of the physics faculty, neither in terms of the design of the programme, and its assessment, nor in their interactions with physics lecturers. Substantial commitment to physics teacher education on the level of institutional leadership has previously been identified to be an important factor for success (Marder et al 2017, Scherr et al 2017, Scherr and Chasteen 2020, T-TEP 2012). Our results suggest that such commitment is also important on the level of interaction with trainees.

Our results can be read as an unfortunate consequence of the common model of teacher education where trainee physics teachers study physics together with other programme groups with no dedicated physics courses (Evagorou et al 2015, Vollmer 2003). Trainee physics teacher groups are often small compared to other physics programmes, making it economically convenient for them to study physics as part of another programme. However, we suggest that the student experiences we have described point towards several potential issues with this approach.

Student experiences of relevance in physics have been connected to better learning outcomes, higher motivation, and enjoyment of physics (Afjar et al 2020, Bennett et al 2016, Descamps et al 2020, Gaffney 2013, Geller et al 2018, Nair and Sawtelle 2019, Plomer et al 2010). Thus, the lack of perceived relevance reported by the trainees in our study, risks significantly affecting their physics learning. The trainees have difficulties understanding how the university physics content they learn is connected to teaching upper secondary school physics. Is it then the job of physics faculty to teach trainees how to transform the university physics they learn to content suited for the upper secondary school level? Naturally, such a question has different answers depending on the particular distribution of responsibility in each individual physics teacher programme. Perhaps a more general answer could be that the physics department has a responsibility in relation to all its students to demonstrate the relevance of the physics they learn for their particular programme path. For trainee physics teachers, a positive experience of learning physics is especially important, since we would like them to pass on this enthusiasm for physics to their future students. Trainee physics teachers in this kind of system risk feeling less motivated, insignificant, and unsuccessful-even when they do well.

Is there, perhaps, a case to be made that the trainees are correct in thinking it is less important for them to do well or be deemed successful in physics? Beyond their introductory physics courses, might it be good enough for trainee physics teachers to simply participate (and gain a pass) in order to get a 'feel' for university physics? Based on our interview data we have no way to determine whether this might be the case, but we do note that there has recently been renewed debate about what physics content trainee teachers need to learn (see for example de Winter and Airey 2019). It is possible that the experience of studying more advanced physics together with other students is potentially useful for future teachers. However, this becomes problematic if providing trainee teachers with such an experience forces them to complete a large part of 
their education as invisible participants on courses designed for other student groups, where they experience little relevance. We suggest that the combination of some trainee teachers seeing themselves as only peripherally interested, together with the courses being organized without taking account of their particular needs and interests, may lead to passivity and lack of engagement - a poor state of affairs on any educational programme. We argue that no matter what physics is deemed to be important for trainees to learn, they will learn it better if they are provided with incentives to work hard and get good grades.

This argument also has bearing on the need to attract students to physics teaching despite higher status and salary in other careers (Watt and Richardson 2008), as well as the belief that trainee teachers are less capable than other physics students (Larsson et al 2021). It has been suggested that the most talented and ambitious students should be recruited to teacher training in order to create highly skilled physics teachers (T-TEP 2012), but there have been few suggestions about how this may be achieved. Moreover, even the most ambitious students will struggle to motivate themselves to work hard to understand physics as long as this knowledge seems to have little bearing on their future. What, then, might provide trainee physics teachers with an incentive to excel? Some trainee teachers in our study were motivated by finding physics fun or interesting, or by nurturing a dream of perhaps doing research in physics in the future. However, the majority of the trainees in our study were not motivated by physics itself, but rather by their future as physics teachers. In our interviews, these students struggle to motivate themselves in their physics courses. One example is Ellen, who says that becoming a physics teacher is what she is passionate about, rather than any particular piece of physics. These students might be motivated by an educational programme where these two are combined. Where a passion for becoming a physics teacher is stimulated by physics courses that are clearly tailored to the needs of physics teachers.

The experiences described in this study paint a picture of a physics classroom culture that is focussed on not appearing unintelligent, which in turn leads to passive learning without asking or answering questions for fear of giving the wrong answer. This finding is similar to earlier observations that students tend to 'retreat into a place of simply trying to look and sound smart so that they can protect their self-esteem' (Van Dusen 2015, p 153). This is concerning, since the activation of students when learning physics has been shown to be of great importance (Fraser et al 2014). Moreover, students who feel able to openly discuss the fact that they do not understand physics content have been shown to have better learning gains (Dowd et al 2015). This is particularly significant for trainee teachers, who will be tasked with creating their own inclusive physics learning environments in the future. For underrepresented groups, breaking the stereotype where physics is connected to intellectual superiority is particularly important (Leslie et al 2015). Learning physics in an environment similar to the one described in this study is unlikely to provide trainees with models that are useful for their own creation of open and inclusive learning environments (Gosling 2020, Gosling and Gonsalves 2020, Hazari et al 2017). Such teaching thus risks perpetuating recruitment problems that physics already has.

Like all qualitative research, our study has limitations in terms of the generalizability and knowledge claims that can be made. To be clear, we make no claim that our findings are generalizable outside the group of trainee physics teachers we interviewed. What we do suggest, however, is that physics lecturers in reading our work, might recognize some of the issues illustrated in this study and adjust their own practice accordingly. Such a response has been variously termed naturalistic generalization (Stake and Trumbull 1982) and fuzzy generalization (Bassey 2001). 


\section{Conclusion and suggestions}

We have reported a case study describing the experiences of trainee physics teachers who study undergraduate physics together with physics and engineering programme students. Specifically, we asked the trainees how they experienced the purpose and goals of their physics studies. Our aim was to provide illustrative examples that might be used by physicists and physics education professionals to reflect on the design of physics teacher education programmes and on their own practice. Our results both complement and confirm aspects of earlier research on physics teacher education. The commitment of physics faculty to physics teacher education (Scherr and Chasteen 2020), promoting physics teaching as an intellectually challenging endeavour (T-TEP 2012) and providing opportunities for physics students to experience relevance (Nair and Sawtelle 2019) have all been identified as important for the successful education of physics teachers. However, few of these earlier suggestions build on empirical studies of trainee physics teachers actual experiences. Our results add the trainee perspective to the research base, showing that trainees' experiences align well with the findings of earlier work.

Based on our findings, we have four suggestions that physics lecturers might like to take into consideration when reflecting on their own practice with respect to trainee physics teachers.

\section{Creating visibility}

Given our findings we suggest that care should be taken to acknowledge the presence and needs of trainee physics teachers in physics courses. This could be achieved on a programme level, by designing physics courses that cater specifically to the needs of trainee teachers-perhaps modelled on some of the successful physics teacher programmes described in the literature (Etkina 2010, McDermott et al 2000, Otero et al 2010). However, for pragmatic reasons, many trainee physics teachers will continue to be taught together with other programme students to some extent. Handled well, such teaching may offer benefits to trainees in terms of providing an authentic experience of university physics. However, the research reported here suggests that such teaching needs to explicitly acknowledge the presence of trainee physics teachers in mixed groups of students, as well as offering dedicated assignments and projects explicitly suited to their needs.

\section{Offering a sense of relevance}

The processes of experiencing relevance and motivation are complex and need to start with the individual student - we cannot force students to experience their course content as relevant. However, we suggest that explicit discussion about how the physics content being taught is connected to trainees' future in teaching together with the use of specific teaching-related examples and the inclusion of guest lecturers from school physics teachers, should give trainees a starting point for finding their own relevance and motivation (Andersson and Johansson 2016).

\section{Creating an incentive to do well in physics}

We further suggest that the grading schemes for physics courses, whether for trainees specifically or those given to several student groups, need to be designed to give trainee teachers an incentive to excel. The highest grades for trainee teachers should correspond to knowledge connected to teaching physics. This does not mean that we suggest that trainee teachers should only learn the exact physics they are going to teach. What it does mean is that efforts should be made to discuss with trainees how higher grades in more advanced courses are relevant to 
trainee teachers. This might involve changing the course examination criteria, or just being explicit in how the existing criteria connect to a future in teaching.

\section{Creating an interactive classroom culture}

Finally, an overwhelming body of research has shown that activating students is key to improving their physics learning. There are a number of tools that have been developed to guide students and teachers towards this goal (Fraser et al 2014). However, the experiences described in this study - a passive classroom culture focussed on giving the right answer-highlight the importance of also addressing aspects of classroom culture that may work against student interactive engagement. Here, some suggestions are to create a safe environment for learning physics that encourages play, promoting effort and growth rather than fixed outcome goals, and asking students for help in designing classroom norms (Van Dusen 2015).

\section{Acknowledgments}

We would like to thank the Swedish Research Council, Project Number VR 2015-01891 for their support for this research and Cedric Linder for help with funding for interview transcription. Thanks to Bor Gregorcic, Anna Danielsson, Eva Lundqvist, and Anders Johansson for reading and commenting on various drafts of this manuscript. Thanks also to the three anonymous reviewers whose suggestions greatly contributed to a better manuscript.

\section{ORCID iDs}

Johanna Larsson (® https://orcid.org/0000-0002-6265-0004

John Airey (1) https://orcid.org/0000-0003-3244-2586

\section{References}

Afjar A M, Musri and Syukri M 2020 Attention, relevance, confidence, satisfaction (ARCS) model on students' motivation and learning outcomes in learning physics J. Phys.: Conf. Ser. 1460012119

Aiello-Nicosia M L and Sperandeo-Mineo R M 2000 Educational reconstruction of physics content to be taught and of pre-service teacher training: a case study Int. J. Sci. Educ. 22 1085-97

Andersson S and Johansson A 2016 Gender gap or program gap? Students' negotiations of study practice in a course in electromagnetism Phys. Rev. Phys. Educ. Res. 12020112

Barthelemy R S and Knaub A V 2020 Gendered motivations and aspirations of university physics students in Finland Phys. Rev. Phys. Educ. Res. 16010133

Bassey M 2001 A solution to the problem of generalisation in educational research: fuzzy prediction $O x f$. Rev. Educ. 27 5-22

Bennett D, Roberts L and Creagh C 2016 Exploring possible selves in a first-year physics foundation class: engaging students by establishing relevance Phys. Rev. Phys. Educ. Res. 12010120

Berge M, Danielsson A and Lidar M 2020 Storylines in the physics teaching content of an upper secondary school classroom Res. Sci. Technol. Educ. 38 63-83

Berry A, Friedrichsen P and Loughran J 2015 Re-examining Pedagogical Content Knowledge in Science Education (New York: Routledge)

Braun V and Clarke V 2006 Using thematic analysis in psychology Qual. Res. Psychol. 3 77-101

Cox S 2014 Perceptions and influences behind teaching practices: do teachers teach as they were taught? Master's Thesis Brigham Young University https://scholarsarchive.byu.edu/etd/5301

de Winter J and Airey J 2019 What makes a good physics teacher? Views from the English stakeholder community Phys. Educ. 55015017 
Descamps I, Moore T and Pollard B 2020 Views from students and professors in a nonmajor introductory physics course: what is interdisciplinarity? Phys. Rev. Phys. Educ. Res. 16020118

Ding L and Zhang P 2016 Making of epistemologically sophisticated physics teachers: a cross-sequential study of epistemological progression from preservice to in-service teachers Phys. Rev. Phys. Educ. Res. 12020137

Dowd J E, Araujo I and Mazur E 2015 Making sense of confusion: relating performance, confidence, and self-efficacy to expressions of confusion in an introductory physics class Phys. Rev. ST Phys. Educ. Res. 11010107

Etkina E 2010 Pedagogical content knowledge and preparation of high school physics teachers Phys. Rev. ST Phys. Educ. Res. 6020110

Etkina E, Gitomer D, Iaconangelo C, Phelps G, Seeley L and Vokos S 2018 Design of an assessment to probe teachers' content knowledge for teaching: an example from energy in high school physics Phys. Rev. Phys. Educ. Res. 14010127

Etkina E, Gregorcic B and Vokos S 2017 Organizing physics teacher professional education around productive habit development: a way to meet reform challenges Phys. Rev. Phys. Educ. Res. 13 010107

European Commission 2004 Increasing Human Resources for Science and Technology in Europe: Report of the High Level Group on Human Resources for Science and Technology in Europe Office for (Official Publications of the European Communities)

European Commission 2015 Science Education for Responsible Citizenship-A Report (EUR 26893 EN) European Commission https://jcom.sissa.it/science-education-responsible-citizenship-report

Evagorou M, Dillon J, Viiri J and Albe V 2015 Pre-service science teacher preparation in Europe: comparing pre-service teacher preparation programs in England, France, Finland and Cyprus J. Sci. Teach. Educ. 26 99-115

Fazio C, Di Paola B and Guastella I 2012 Prospective elementary teachers' perceptions of the processes of modeling: a case study Phys. Rev. ST Phys. Educ. Res. 8010110

Flick U, Flick U, Kvale S, Angrosino M V, Barbour R S, Banks M, Gibbs G, Rapley T and Flick U 2007 The Sage Qualitative Research Kit (London: SAGE)

Forsman J 2015 Complexity theory and physics education research: the case of student retention in physics and related degree programmes Doctoral Thesis, Comprehensive Summary Uppsala University http://diva-portal.org/smash/record.jsf?pid=diva2:846064

Frågåt T, Henriksen E K and Tellefsen C W 2021 Pre-service science teachers' and in-service physics teachers' views on the knowledge and skills of a good teacher NorDiNa

Fraser J M, Timan A L, Miller K, Dowd J E, Tucker L and Mazur E 2014 Teaching and physics education research: bridging the gap Rep. Prog. Phys. 77032401

Gaffney J D H 2013 Education majors' expectations and reported experiences with inquiry-based physics: implications for student affect Phys. Rev. ST Phys. Educ. Res. 9010112

Gee J P 2005 An Introduction to Discourse Analysis: Theory and Method 2nd edn (New York: Routledge)

Geller B D, Turpen C and Crouch C H 2018 Sources of student engagement in introductory physics for life sciences Phys. Rev. Phys. Educ. Res. 14010118

Gosling C and Gonsalves A J 2020 Lessons from research exploring the underrepresentation of women in physics Phys. Teach. 58 342-4

Gosling C 2020 Conclusions part II: implications of identity research for upper secondary educators Physics Education and Gender: Identity as an Analytic Lens for Research ed A J Gonsalves and A T Danielsson (Cham: Springer) pp 177-83

Guba E G and Lincoln Y S 1982 Epistemological and methodological bases of naturalistic inquiry Educ. Commun. Technol. 30 233-52

Guilfoyle L, McCormack O and Erduran S 2020 The 'tipping point' for educational research: the role of pre-service science teachers' epistemic beliefs in evaluating the professional utility of educational research Teach. Teach. Educ. 90103033

Hazari Z, Brewe E, Goertzen R M and Hodapp T 2017 The importance of high school physics teachers for female students' physics identity and persistence Phys. Teach. 55 96-9

Hazari Z, Potvin G, Lock R M, Lung F, Sonnert G and Sadler P M 2013 Factors that affect the physical science career interest of female students: testing five common hypotheses Phys. Rev. ST Phys. Educ. Res. 9020115

Hodapp T and Hazari Z 2015 Women in physics: why so few? APS News 248

Kaltakci-Gurel D, Eryilmaz A and McDermott L C 2016 Identifying pre-service physics teachers' misconceptions and conceptual difficulties about geometrical optics Eur. J. Phys. 37045705 
Koponen M, Asikainen M, Viholainen A and Hirvonen P 2016 Teachers and their educators-views on contents and their development needs in mathematics teacher education Math. Enthus. 13 149-70 https://scholarworks.umt.edu/tme/vol13/iss 1/10

Körhasan N D 2015 The place of learning quantum theory in physics teacher education: motivational elements arising from the context Educ. Sci. Theor. Pract. 15 1087-101

Kvale S 1996 Interviews: An Introduction to Qualitative Research Interviewing (Thousand Oaks: SAGE)

Larsson J, Airey J, Danielsson A T and Lundqvist E 2018 A Fragmented Training Environment: Discourse Models in the Talk of Physics Teacher Educators Res. Sci. Educ. 50 2559-85

Larsson J, Airey J and Lundqvist E 2021 Swimming against the Tide: Five Assumptions about Physics Teacher Education Sustained by the Culture of Physics Departments J. Sci. Teach. Educ. 0 1-18

Leslie S-J, Cimpian A, Meyer M and Freeland E 2015 Expectations of brilliance underlie gender distributions across academic disciplines Science 347 262-5

Loewenberg Ball D, Thames M H and Phelps G 2008 Content knowledge for teaching: what makes it special? J. Teach. Educ. 59 389-407

Mäntylä T 2011 Didactical Reconstructions for Organizing Knowledge in Physics Teacher Education (Helsinki: Department of Physics, University of Helsinki)

Mäntylä T and Koponen I T 2007 Understanding the role of measurements in creating physical quantities: a case study of learning to quantify temperature in physics teacher education Sci. Educ. 16 291-311

Marder M, Brown R C and Plisch M 2017 Recruiting Teachers in High-Needs STEM Fields: A Survey of Current Majors and Recent STEM Graduates American Physical Society http://aps.org/policy/ reports/popa-reports/stemteachers.cfm

Massolt J and Borowski A 2020 Perceived relevance of university physics problems by pre-service physics teachers: personal constructs Int. J. Sci. Educ. 42 167-89

McDermott L C 1990 A perspective on teacher preparation in physics and other sciences: the need for special science courses for teachers Am. J. Phys. 58 734-42

McDermott L C, Shaffer P S and Constantinou C P 2000 Preparing teachers to teach physics and physical science by inquiry Phys. Educ. 35 411-6

Milner-Bolotin M, Egersdorfer D and Vinayagam M 2016 Investigating the effect of question-driven pedagogy on the development of physics teacher candidates' pedagogical content knowledge Phys. Rev. Phys. Educ. Res. 12020128

Mishra P and Koehler M J 2006 Technological pedagogical content knowledge: a framework for teacher knowledge Teach. Coll. Rec. 108 1017-54

Nachtigall D K 1990 What is wrong with physics teachers' education? Eur. J. Phys. 111

Nair A and Sawtelle V 2019 Operationalizing relevance in physics education: using a systems view to expand our conception of making physics relevant Phys. Rev. Phys. Educ. Res. 15020121

Oleson A and Hora M T 2014 Teaching the way they were taught? Revisiting the sources of teaching knowledge and the role of prior experience in shaping faculty teaching practices High Educ. 68 29-45

Osborne J and Dillon J 2008 Science Education in Europe: Critical Reflections vol 13 (London: The Nuffield Foundation) https://nuffieldfoundation.org/about/publications/science-education-ineurope-critical-reflections

Otero V, Pollock S and Finkelstein N 2010 A physics department's role in preparing physics teachers: the Colorado learning assistant model Am. J. Phys. 78 1218-24

Park S and Oliver J S 2008 Revisiting the conceptualisation of pedagogical content knowledge (PCK): PCK as a conceptual tool to understand teachers as professionals Res. Sci. Educ. 38 261-84

Plomer M, Jessen K, Rangelov G and Meyer M 2010 Teaching physics in a physiologically meaningful manner Phys. Rev. ST Phys. Educ. Res. 6020116

Şahin E and Yağbasan R 2012 Determining which introductory physics topics pre-service physics teachers have difficulty understanding and what accounts for these difficulties Eur. J. Phys. 33 $315-25$

Scherr R E and Chasteen S V 2020 Initial findings of the physics teacher education program analysis rubric: what do thriving programs do? Phys. Rev. Phys. Educ. Res. 16010116

Scherr R E, Plisch M and Goertzen R M 2015 Physics teacher production: patterns of institutional engagement and faculty theories Physics Education Research Conf. 2015 pp 303-6 https://doi.org/10. 1119/perc.2015.pr.071

Scherr R E, Plisch M and Goertzen R M 2017 Sustaining physics teacher education coalition programs in physics teacher education Phys. Rev. Phys. Educ. Res. 13010111 
Seeley L, Vokos S and Etkina E 2019 Examining physics teacher understanding of systems and the role it plays in supporting student energy reasoning Am. J. Phys. 87 510-9

Selçuk G S 2010 Addressing pre-service teachers' understandings and difficulties with some core concepts in the special theory of relativity Eur. J. Phys. 32 1-13

Shulman L S 1986 Those who understand: knowledge growth in teaching Educ. Res. 15 4-14

Shulman L 1987 Knowledge and teaching: foundations of the new reform Harv. Educ. Rev. 57 1-23

Stake R E and Trumbull D 1982 Naturalistic generalizations Rev. J. Philos. Soc. Sci. 7 1-12

Swedish Research Council 2017 Good Research Practice (Swedish Research Council) https://vr.se/ english/analysis/reports/our-reports/2017-08-31-good-research-practice.html

T-TEP 2012 Transforming the Preparation of Physics Teachers: A Call to Action American Physical Society http://phystec.org/webdocs/2013TTEP.pdf

Taylor P C 2014 Contemporary qualitative research: toward an integral research perspective Handbook of Research on Science Education vol 2 ed S K Abell and N G Lederman (New York: Routledge) pp 38-54

Teach for Sweden 2020 Morgondagens vuxna behöver en ny ledare. Är det du? Teach for Sweden https:// teachforsweden.se/

Thompson J R, Christensen W M and Wittmann M C 2011 Preparing future teachers to anticipate student difficulties in physics in a graduate-level course in physics, pedagogy, and education research Phys. Rev. ST Phys. Educ. Res. 7010108

Tracy S J 2010 Qualitative quality: eight 'big-tent' criteria for excellent qualitative research Qual. Inq. $16837-51$

Ulriksen L 2009 The implied student Stud. High Educ. 34 517-32

Ünlü P 2010 Pre-service physics teachers' ideas on size, visibility and structure of the atom Eur. J. Phys. 31 881-92

Van Dusen B 2015 The roots of physics students' motivations: fear and Integrity (arXiv:1502.04256 [Physics])

Viennot L 2019 Misleading mathematical legitimacy and critical passivity: discussing the irreversible expansion of an ideal gas with beginning teachers Eur. J. Phys. 40045701

Vollmer M 2003 Physics teacher training and research in physics education: results of an inquiry by the European Physical Society Eur. J. Phys. 24 131-47

Watt H M G and Richardson P W 2008 Motivations, perceptions, and aspirations concerning teaching as a career for different types of beginning teachers Learn. Instruct. 18 408-28 